\title{
Extracranial Sources of S100B Do Not Affect Serum Levels
}

\author{
Nancy Pham ${ }^{1}$, Vincent Fazio ${ }^{2}$, Luca Cucullo ${ }^{2}$, Qingshan Teng ${ }^{3}$, Peter Biberthaler ${ }^{4}$, Jeffrey J. Bazarian ${ }^{5}$, \\ Damir Janigro ${ }^{1 *}$
}

1 Cleveland Clinic Lerner College of Medicine of Case Western Reserve University, Cleveland Clinic Foundation, Cleveland, Ohio, United States of America, 2 Department of Cell Biology, Cleveland Clinic Foundation, Cleveland, Ohio, United States of America, 3 Neurological Surgery, Cleveland Clinic Foundation, Cleveland, Ohio, United States of America, $\mathbf{4}$ Surgical Department Munich Central, Ludwig-Maximilians-Universität Munich, Munich, Germany, 5 Department of Emergency Medicine, University of Rochester School of Medicine, Rochester, New York, United States of America

\begin{abstract}
S100B, established as prevalent protein of the central nervous system, is a peripheral biomarker for blood-brain barrier disruption and often also a marker of brain injury. However, reports of extracranial sources of S100B, especially from adipose tissue, may confound its interpretation in the clinical setting. The objective of this study was to characterize the tissue specificity of S100B and assess how extracranial sources of S100B affect serum levels. The extracranial sources of S100B were determined by analyzing nine different types of human tissues by ELISA and Western blot. In addition, brain and adipose tissue were further analyzed by mass spectrometry. A study of 200 subjects was undertaken to determine the relationship between body mass index (BMI) and S100B serum levels. We also measured the levels of S100B homo- and heterodimers in serum quantitatively after blood-brain barrier disruption. Analysis of human tissues by ELISA and Western blot revealed variable levels of S100B expression. By ELISA, brain tissue expressed the highest S100B levels. Similarly, Western blot measurements revealed that brain tissue expressed high levels of S100B but comparable levels were found in skeletal muscle. Mass spectrometry of brain and adipose tissue confirmed the presence of S100B but also revealed the presence of S100A1. The analysis of 200 subjects revealed no statistically significant relationship between BMI and S100B levels. The main species of S100B released from the brain was the B-B homodimer. Our results show that extracranial sources of S100B do not affect serum levels. Thus, the diagnostic value of $\mathrm{S100B}$ and its negative predictive value in neurological diseases in intact subjects (without traumatic brain or bodily injury from accident or surgery) are not compromised in the clinical setting.
\end{abstract}

Citation: Pham N, Fazio V, Cucullo L, Teng Q, Biberthaler P, et al. (2010) Extracranial Sources of S100B Do Not Affect Serum Levels. PLoS ONE 5(9): e12691. doi:10.1371/journal.pone.0012691

Editor: Maria A. Deli, Hungarian Academy of Sciences, Hungary

Received June 24, 2010; Accepted August 11, 2010; Published September 10, 2010

Copyright: ( 2010 Pham et al. This is an open-access article distributed under the terms of the Creative Commons Attribution License, which permits unrestricted use, distribution, and reproduction in any medium, provided the original author and source are credited.

Funding: This study was supported by RO1 NS43284, RO1 NS38195, R21 HD057256 to Damir Janigro. It was also supported by “A Prospective Pilot Study on S100B in TBI" funded by Roche Diagnostics and by the Cleveland Clinic-Swedish Satellite Laboratory Feasibility Project, Federal Appropriation Washington State. None of the funding agencies had role in study design, data collection and analysis, decision to publish, or preparation of the manuscript.

Competing Interests: The authors have declared that no competing interests exist.

*E-mail: janigrd@ccf.org

\section{Introduction}

$\mathrm{S} 100 \mathrm{~B}$, a protein produced primarily by brain astrocytes, is an established peripheral biomarker of blood-brain-barrier permeability associated with various CNS (central nervous system) injuries [1,2]. Elevated levels accurately reflect the presence of neuropathological conditions including traumatic head injuries [3-5], psychiatric disorders [6], cerebrovascular insults [7] and neurodegenerative diseases [8], while normal levels reliably exclude major CNS pathology $[4,9,10]$. Its potential clinical use in the therapeutic decision making process is substantiated by a vast body of literature validating variations in serum 100B levels with standard modalities for prognosticating the extent of CNS damage: alterations in neuroimaging, cerebrospinal pressure, and other brain molecular markers (neuron specific enolase, glial fibrillary acidic protein) $[11,12]$. Thus, the major advantage of using S100B is that elevations in serum can be easily measured, providing a sensitive measure to help rule out major CNS dysfunction
An important application of serum S100B testing is the selection of patients with minor head injury who do not need further neuroradiological evaluation, as studies comparing CT (computerized tomography) scans and S100B levels have demonstrated $\mathrm{S} 100 \mathrm{~B}$ values below $0.1 \mathrm{ng} / \mathrm{mL}$ are associated with low risk of obvious neuroradiological changes (such as intracranial hemorrhage) or significant clinical sequelae [10]. In addition, several papers have shown that the high negative predictive value $(\mathrm{NPV}=\mathrm{TN} /(\mathrm{TN}+\mathrm{FN})$, where $\mathrm{TN}=$ true negative and $\mathrm{FN}=$ false negative) of $\mathrm{S100B}$ in several neurological conditions is due to the fact that serum S100B levels reflect blood-brain barrier permeability changes even in absence of neuronal injury [1-9]. Thus, serum S100B levels may increase prior to a significant change in neurological function, or neuronal cell death, which is in accordance to its function as an astroglial and non-neuronal protein marker. This is an important clinical finding inasmuch S100B levels in the normal range rule out cerebrovascular damage and injury to the CNS in nearly $99 \%$ of patients by neurological imaging [10-13]. 
Recently, controversy has arisen with regards to the brain specificity of this protein. Several lines of evidence suggest that extracerebral sources contribute to S100B serum levels [13]. For example, in multi-organ system trauma without traumatic head injury, elevations in serum $\mathrm{S} 100 \mathrm{~B}$ levels collectively reflect traumatized fat, muscles, or bones since the blood-brain barrier remains intact in these situations and therefore, cannot account for the systemic rise in S100B levels. Similarly, shed blood from cardiac surgery displayed heightened levels without apparent head injury [14]. Marathon runners, joggers, basketball players, ice hockey players, and boxers also have high S100B levels after engaging in their respective physical activity, which may be the result of both BBB (blood-brain barrier) opening and muscular release [15-17].

The objective of this current study was to determine if tissue sources, outside the brain, contribute significantly to serum levels of S100B. In this study, we characterized by Western blot the expression of S100B in human tissue using two different antibodies and corroborated this data with mass spectrometry. We then assessed how expression in these tissues affects the current clinical methods for detection of $\mathrm{S} 100$ by using the LIAISON ${ }^{\circledR}$ S100 or LIAMAT systems (Sangtec-Diasorin), and the Elecsys system (Roche Diagnostics). Finally, we analyzed 200 subjects to determine if adiposity or fat S100B affected serum levels.

\section{Methods}

\section{Human Subjects}

All studies were performed in accordance with the Declaration of Helsinki and written approval by the IRB Committee at the Cleveland Clinic. All samples (blood and tissue) were obtained by written informed consent and given a coded identifier to retain subject anonymity. Tissue samples were obtained as surplus tissue from various medical procedures conducted at the Cleveland Clinic, generously provided by the department of Pathology. For the purpose of this study we analyzed 200 subjects, consisting of 155 patients and 45 controls (Table 1). Note that our patient population comprised of individuals with a broad spectrum of ages, races, and pathologies, which ranges from psychiatric disorders to brain tumors. We also recruited a large number of volunteers without any pathology or psychiatric condition, as detected by a psychiatrist delivering a brief psychiatric exam. Samples were analyzed by different techniques, the details of which are presented in the Methods Section and below. We analyzed tissue protein contents by antibody-dependent assays or by mass spectrometry (MS). When possible, two antibodies were used for the detection of different antigen regions in the S100B protein. BMI (body mass index) was calculated based on the weight (in kilograms) divided by the square of the patient's height (in meters) taken from the medical record.

\section{BBB Disruption}

The Cleveland Clinic Brain Tumor Institute provides a treatment called blood-brain barrier disruption for primary CNS lymphomas. All procedures were performed after informed consent was obtained using protocols approved by the Cleveland Clinic Foundation IRB. In this protocol, intra-arterial mannitol $(1.4 \mathrm{M})$ is administered via a carotid or vertebral artery, and BBB disruption was confirmed by contrast CT immediately after chemotherapy. The details are described elsewhere [18].

\section{Tissue Protein Extraction}

Proteins were extracted from various tissues using the Millipore Total Protein Extraction Kit (Chemicon subsidiary, Temecula, CA). Briefly, tissues were weighed, chopped into small pieces, and kept on dry ice. Then $1 \mathrm{X}$ TM buffer [13 mL of HEPES (pH 7.9), $\mathrm{MgCl}_{2}, \mathrm{KCl}$, EDTA, sucrose, glycerol, sodium deoxycholate, NP40 , sodium orthovanadate] and a protease inhibitor cocktail was added to each tissues at $2.5 \mathrm{~mL}$ per gram of tissue and put on ice for 5 minutes. The tissue was homogenized for 20 seconds and then put on dry ice for 15 seconds. This cycle was repeated 3 times. The homogenized tissues were rotated at $4^{\circ} \mathrm{C}$ for 20 minutes and centrifuged at $11,000 \mathrm{rpm}$ at $4^{\circ} \mathrm{C}$ for 20 minutes. The supernatant was collected and stored at $-80^{\circ} \mathrm{C}$ until analyzed further.

\section{Western Blots}

Protein concentration was determined by the Bradford assay method (Bio-Rad, Hercules, CA). Total proteins (50 $\mu \mathrm{g} / \mathrm{lane}$ ) were separated on 10-20\% polyacrylamide gels with SDS-PAGE at

Table 1. Patient Characteristics.

\begin{tabular}{|c|c|c|c|c|c|c|c|c|c|c|c|c|c|c|c|}
\hline Grouping & $\mathbf{N}$ & Age & $\begin{array}{l}\text { Age } \\
\text { Range }\end{array}$ & $\begin{array}{l}\text { Height } \\
\text { (cm) }\end{array}$ & $\begin{array}{l}\text { Height } \\
\text { Range } \\
\text { (cm) }\end{array}$ & $\begin{array}{l}\text { Weight } \\
\text { (kg) }\end{array}$ & $\begin{array}{l}\text { Weight } \\
\text { Range } \\
\text { (kg) }\end{array}$ & $\begin{array}{l}\text { BMI } \\
\left(\mathrm{kg} / \mathrm{m}^{2}\right)\end{array}$ & $\begin{array}{l}\text { BMI } \\
\text { Range } \\
\left(\mathbf{k g} / \mathbf{m}^{2}\right)\end{array}$ & $\begin{array}{l}\text { S100B } \\
\text { (ng/mL) }\end{array}$ & $\begin{array}{l}\text { S100B } \\
\text { Range } \\
\text { (ng/mL) }\end{array}$ & $\begin{array}{l}\% \\
\text { Female }\end{array}$ & $\begin{array}{l}\text { Cau- } \\
\text { casian }\end{array}$ & $\begin{array}{l}\text { African } \\
\text { American }\end{array}$ & Other \\
\hline $\begin{array}{l}\text { Ped. } \\
\text { Controls }\end{array}$ & 20 & $\begin{array}{l}16.6 \\
(1.1)\end{array}$ & $14-18$ & $\begin{array}{l}171.3 \\
(7.3)\end{array}$ & $\begin{array}{l}161- \\
191\end{array}$ & $\begin{array}{l}67.3 \\
(16.9)\end{array}$ & $45-118$ & $22.9(5.1)$ & $16.7-38.4$ & $\begin{array}{l}0.11 \\
(0.09)\end{array}$ & $\begin{array}{l}0.03- \\
0.42\end{array}$ & 55.0 & 14 & 1 & 5 \\
\hline $\begin{array}{l}\text { Ped. } \\
\text { (Non-Psych) }\end{array}$ & 25 & $\begin{array}{l}14.3 \\
(3.3)\end{array}$ & 8-18 & $\begin{array}{l}156.9 \\
(18.9)\end{array}$ & $\begin{array}{l}120- \\
185\end{array}$ & $\begin{array}{l}65.6 \\
(28.9)\end{array}$ & $21-111$ & $25.3(7.7)$ & $12.9-38.5$ & $\begin{array}{l}0.23 \\
(0.17)\end{array}$ & $\begin{array}{l}0.05- \\
0.70\end{array}$ & 40.0 & 19 & 1 & 5 \\
\hline $\begin{array}{l}\text { Ped. } \\
\text { Psychotic }\end{array}$ & 39 & $\begin{array}{l}14.3 \\
(2.6)\end{array}$ & $10-18$ & $\begin{array}{l}162.6 \\
(13.4)\end{array}$ & $\begin{array}{l}137- \\
186\end{array}$ & $\begin{array}{l}68.3 \\
(29.0)\end{array}$ & $27-205$ & $25.4(9.5)$ & $11.3-76.2$ & $\begin{array}{l}0.26 \\
(0.23)\end{array}$ & $\begin{array}{l}0.02- \\
1.11\end{array}$ & 43.6 & 18 & 16 & 5 \\
\hline $\begin{array}{l}\text { Adult } \\
\text { Controls }\end{array}$ & 25 & $\begin{array}{l}39.1 \\
(11.1)\end{array}$ & $22-60$ & $\begin{array}{l}169.1 \\
(8.1)\end{array}$ & $\begin{array}{l}147- \\
183\end{array}$ & $\begin{array}{l}68.1 \\
(9.3)\end{array}$ & $50-82$ & $23.8(2.8)$ & $19.1-31.8$ & $\begin{array}{l}0.08 \\
(0.05)\end{array}$ & $\begin{array}{l}0.04- \\
0.27\end{array}$ & 40.0 & 13 & 1 & 11 \\
\hline $\begin{array}{l}\text { Adult } \\
\text { (Non-SVID) }\end{array}$ & 22 & $\begin{array}{l}62.5 \\
(9.5)\end{array}$ & $47-80$ & $\begin{array}{l}174.1 \\
(10.1)\end{array}$ & $\begin{array}{l}155- \\
189\end{array}$ & $\begin{array}{l}79.1 \\
(18.4)\end{array}$ & $54-127$ & $26.1(6.1)$ & $19.3-47.8$ & $\begin{array}{l}0.22 \\
(0.29)\end{array}$ & $\begin{array}{l}0.01- \\
0.13\end{array}$ & 27.3 & 20 & 2 & 0 \\
\hline $\begin{array}{l}\text { Adult } \\
\text { (SVID) }\end{array}$ & 59 & $\begin{array}{l}65.8 \\
(8.0)\end{array}$ & $49-85$ & $\begin{array}{l}169.6 \\
(10.5)\end{array}$ & $\begin{array}{l}146- \\
203\end{array}$ & $\begin{array}{l}78.8 \\
(16.7)\end{array}$ & $37-125$ & $27.3(5.1)$ & $15.6-40.7$ & $\begin{array}{l}0.18 \\
(0.15)\end{array}$ & $\begin{array}{l}0.01- \\
0.71\end{array}$ & 40.7 & 53 & 6 & 0 \\
\hline BBBD & 10 & $\begin{array}{l}53.6 \\
(15.8)\end{array}$ & $21-72$ & $\begin{array}{l}165.3 \\
(7.8)\end{array}$ & $\begin{array}{l}152- \\
178\end{array}$ & $\begin{array}{l}73.8 \\
(23.0)\end{array}$ & 29-105 & 26.8(7.4) & $10.6-36.0$ & $\begin{array}{l}0.14 \\
(0.04)\end{array}$ & $\begin{array}{l}0.07- \\
0.22\end{array}$ & 80.0 & 10 & 0 & 0 \\
\hline
\end{tabular}

This table describes the patient characteristics of our study patient populations [mean value $+/-$ (standard deviation)].

doi:10.1371/journal.pone.0012691.t001 
$80 \mathrm{~V}$ and transferred onto a polyvinylidene difluoride membrane (Millipore Corp., Bedford, MA) by electroblotting at $100 \mathrm{~V}$ of constant voltage for 1 hour. After blocking with TBST and milk (Tris-buffered saline, $0.05 \%$ milk powder, and 0.05\% Tween 20) for at least 2 hours, the membrane was probed overnight at $4^{\circ} \mathrm{C}$ either with the Sangtec-Diasorin or OriGene S100B primary antibody (1:1000). The OriGene monoclonal antibody was made by immunizing against a synthetic peptide corresponding to residues on the $\mathrm{C}$-terminus of human S100B. The polyclonal Sangtec antibody was raised against the whole human protein. These antibodies were selected because they target different regions of the S100B protein (see legend of Figure 1). The Sangtec antibody was also chosen for Western blot analysis because it constitutes the capture antibody of the LIAISON kit (Figures 2A, B). After a series of washes, the membrane was incubated with secondary horseradish peroxidase-conjugated anti-goat IgG antibody (rabbit or rat) for 2 hours. Western blots were visualized by enhanced chemiluminescence reagent (ECL Plus, Amersham Biosciences, Piscataway, NJ). The dilution for the Sangtec antibody, which is not commercially available, was derived from a previous study [14].

\section{Relative Density on Western Blots}

Western blots were scanned on a scanner interfaced with a PC using HP Precision Scan Pro 3.02 analysis software (HewlettPackard Co., Palo Alto, CA). The scanned grayscale images were saved in an uncompressed TIFF format and further analyzed using software specifically designed for measuring grayscale image density, developed by Nonlinear USA, Inc. (Durham, NG) PhoretixTM ID (Version 2003.01).

\section{Immunoassay Determination}

We used colorimetric immunosorbent assay, Sangtec ${ }^{\circledR} 100$ ELISA, by DiaSorin, Inc. (Stillwater, MN) to quantify S100B. The

\section{A}

\section{Sangtec antibody}
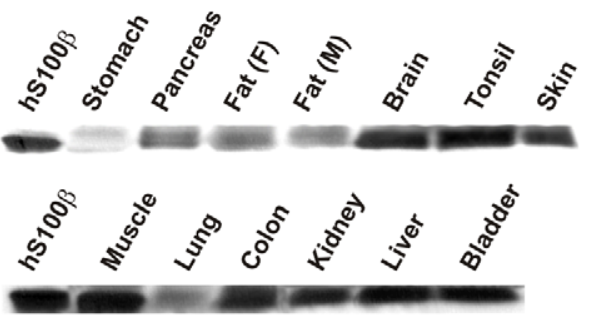

\section{OriGene}
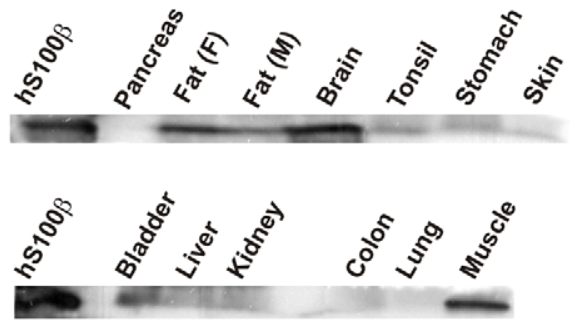
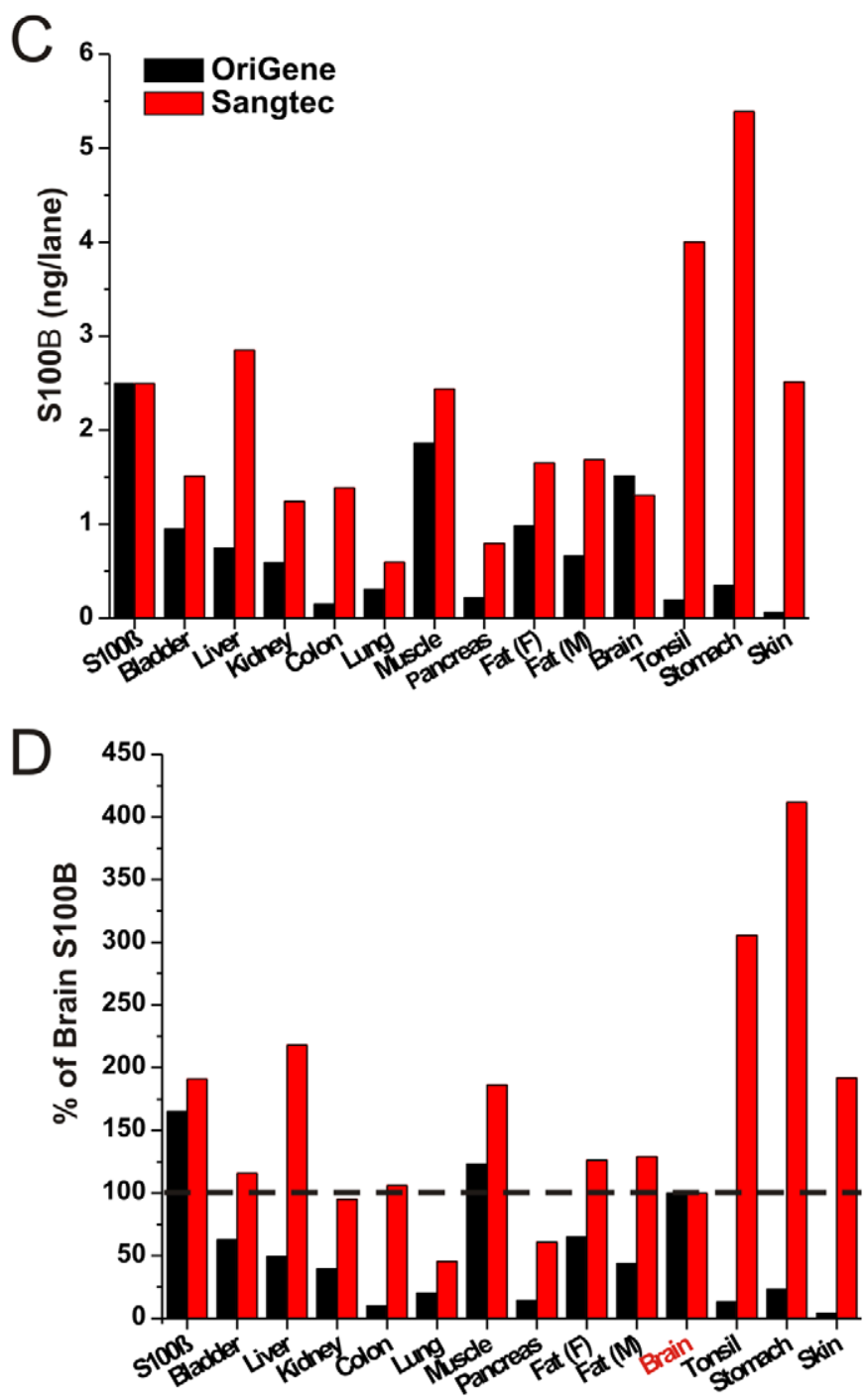

Figure 1. S100B Antibody Comparison. Twelve different types of human tissues were assessed for S100B expression by two different antibodies by Western blot. The OriGene monoclonal antibody was made by immunizing against a synthetic peptide corresponding to residues on the Cterminus of human S100B. The polyclonal Sangtec antibody was raised against the whole human protein. (A) shows the tissue specific expression level of S100B using the Sangtec-Diasorin antibody and (B) OriGene antibody after Western blot analysis. Regardless of the antibody used, S100B was found in tissues other than brain. (C) We quantified and compared the results of the two Western blots obtained by the two different antibodies as well as (D) this data normalized to brain tissue. The rank order of S100B expression is different depending on the antibody used. doi:10.1371/journal.pone.0012691.g001 

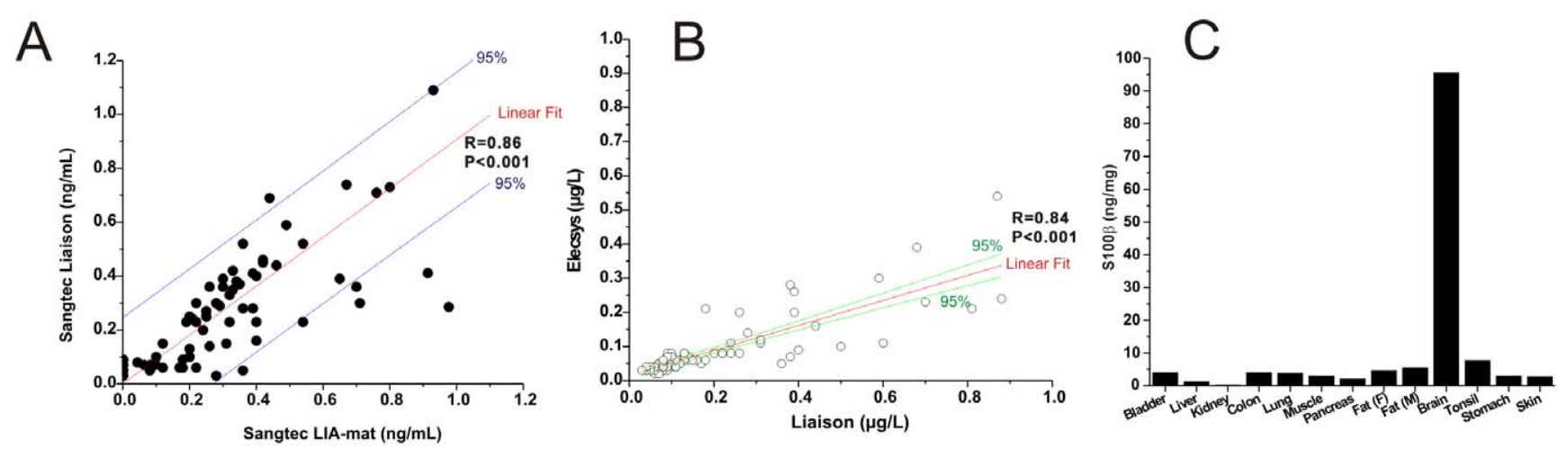

Figure 2. Extracranial Detection of S100B. Extracranial sources of $\mathrm{S} 100 \mathrm{~B}$ revealed on Western blots do not affect the clinical detection of S100B using the Sangtec-Diasorin immunoassay. (A) The results of two clinically relevant Sangtec-Diasorin immunoassay systems; the fully automated Liaison (x-axis) was compared with the manual LIA-mat assay kit. There was good correlation between the two systems. (B) A good correlation existed between two automated (Elecsys by Roche Diagnostics and Liaison by DiaSorin) immunoassays for S100B. (C) The same human tissue protein extracts used for Western blotting previously were analyzed with the Sangtec-Diasorin immunoassay. In contrast to what we found in Western blots, the brain is the main chief expressor detected by this method.

doi:10.1371/journal.pone.0012691.g002

limit of detection is $0.03 \mathrm{ng} / \mathrm{mL}$. We also used the Canag/ Fujirebio system by Fujirebio Diagnostics, Inc. (Tokyo, Japan) to measure various mono- and hetero- dimers of S100B. The Elecsys system (Roche Diagnostics, Indianapolis, IN) was used as well for the purpose of measuring S100B.

\section{Mass Spectrometry}

We used a LC-MS system Finnigan LCQ-Deca ion trap mass spectrometer system with a Protana microelectrospray ion source interfaced to a self-packed $10 \mathrm{~cm} \times 75 \mathrm{um}$ id Phenomenex Jupiter C18 reversed-phase capillary chromatography column. Data were analyzed by using all CID spectra collected in the experiment to search the National Center of Biotechnology Information (NCBI) non-redundant database with the search program TurboSequest. All matching spectra were verified by manual interpretation. The interpretation process was also aided by using the programs Mascot and Fasta to perform additional searches, as needed.

\section{Statistical Methods}

Data are presented as mean \pm standard deviation $(\mathrm{SD}) . \mathrm{JMP}^{\circledR}$ 8.0 (Cary, NG) was used for statistical analysis. Correlation plots were produced using statistical software by the Origin Lab Corporation (versions 7.0 and higher, Northampton, MA) to calculate correlation coefficients $(\mathrm{R})$ and 95\% confidence limits. Significant difference or correlation was assessed by P-values of $<0.05$, calculated using the Student's t-statistic.

\section{Results}

We first analyzed S100B protein content in a variety of tissue samples (Table 2). Western blot analysis revealed that, regardless of the antibody used, S100B is found in tissues other than brain. The results in Figure $1 \mathrm{~A}$ and $1 \mathrm{~B}$ show protein signals obtained with the Sangtec or OriGene antibody.

The results presented thus far were obtained with two different antibodies directed towards the same antigen, yet these results were not quantitatively consistent. To rule out that the measured signal may be due to protein other than S100B, we analyzed the molecular identity of selected lanes shown in Figure 1A and 1B by MS.

The two antibodies gave comparable but not identical results. While both revealed a strong signal from brain tissue, muscle and fat also exhibited strong levels of expression. The data were quantified to construct the bar graph shown in Figure $1 \mathrm{C}$ where the values are expressed in nanograms per lane. An added standard of S100B was used to quantify S100B expression in tissues. In addition, we compared these expression levels to brain tissue as shown in Figure 1D. Note that when data are normalized to brain expression, significant levels were seen in extracranial tissues and the extent of this phenomenon depended on the antibody used.

\section{Molecular Identity of the S100B Signal}

MS analysis confirmed that the brain tissue signal, consistent by molecular weight with S100B, was indeed this protein (Table 3). When the same lanes were isolated from fat samples, S100B expression was similarly found. We chose fat tissue because it was most consistently reported in the literature to contribute to

Table 2. Surgical Specimen Characteristics.

\begin{tabular}{lllll}
\hline & & & & \\
\hline Tissue Specimen & $\begin{array}{l}\text { Primary } \\
\text { Diagnosis }\end{array}$ & Sex & Age & Race \\
\hline Bladder & Bladder Cancer & M & 65 & Caucasian \\
Liver & Liver Cancer & M & 57 & Caucasian \\
Kidney & RCC & M & 71 & Caucasian \\
Colon & UC & M & 53 & Caucasian \\
Lung & Lung Cancer & M & 80 & Caucasian \\
Muscle & Sarcoma & M & 67 & Black \\
Pancreas & Cyst & F & 42 & Caucasian \\
Fat & Sarcoma & F & 81 & Black \\
Fat & Crohn's Disease & M & 50 & Caucasian \\
Brain & Epilepsy & M & 35 & Hispanic \\
Tonsil & Hypotrophy & F & 33 & Caucasian \\
Stomach & Unknown & M & 54 & Caucasian \\
Skin & Thigh Mass & M & 43 & Black \\
\hline
\end{tabular}

Table 2 details the patient characteristics of the surgical specimens used for Western blotting and ELISA analysis. RCC $=$ Renal Cell Carcinoma, UC = Ulcerative Colitis.

doi:10.1371/journal.pone.0012691.t002 
Table 3. Mass Spectrometry Characterization of Protein Bands.

\begin{tabular}{|c|c|c|}
\hline Tissue Type & Proteins Detected & Nomenclature \\
\hline Human Brain & $\mathrm{S} 100 \mathrm{~B}, \mathrm{~S} 100 \mathrm{~A}$ & $\begin{array}{l}\text { S100 calcium binding protein A1 (Acc\# 5454032,11 kDa) } \\
\text { S100 protein, beta polypeptide (Acc\# 5454034, } 11 \mathrm{kDa})\end{array}$ \\
\hline Human Fat (F) & $\mathrm{S} 100 \mathrm{~B}, \mathrm{~S} 100 \mathrm{~A}$ & $\begin{array}{l}\text { S100 calcium binding protein A1 (Acc\# 5454032, } 11 \mathrm{kDa}) \\
\text { S100 protein, beta polypeptide (Acc\# 5454034, } 11 \mathrm{kDa})\end{array}$ \\
\hline Human Fat (M) & $\mathrm{S} 100 \mathrm{~B}, \mathrm{~S} 100 \mathrm{~A}$ & $\begin{array}{l}\text { S100 calcium binding protein A1 (Acc\# 5454032, } 11 \mathrm{kDa} \text { ) } \\
\text { S100 protein, beta polypeptide (Acc\# 5454034, } 11 \mathrm{kDa} \text { ) }\end{array}$ \\
\hline
\end{tabular}

Mass spectrometry analysis revealed that human brain and fat tissue contained S100B as well as the presence of another protein of the S100 family, namely S100A. doi:10.1371/journal.pone.0012691.t003

elevated serum S100B levels $[19,20]$. In addition to S100B, MS analysis also revealed the presence of another protein of the $\mathrm{S} 100$ family, namely S100Al [21].

\section{Results with a Clinically Relevant Platform}

Most of the clinical results dealing with the utilization of $\mathrm{S} 100 \mathrm{~B}$ as a predictor of neurological disorders were obtained with one of several immunoassays that are commercially available (for a complete recent summary see Goncalves et al., [13]).

We measured S100B by ELISA (Sangtec-LIAISON; Figure 2C). With the LIAISON system, brain was the chief expressor, while other tissues contributed less significantly, if at all to the signal. In particular, neither muscle nor fat gave a significant signal as it did in the Western blots. Thus, tissue samples S100B content was substantially different when using ELISA vs. Western (compare Figure 2C and Figure 1C).

In addition to this commercially available immunoassay, previous literature dealing with clinical samples has often used an automated version of the same test [13]. The results of a direct comparison between the automated and manual test are shown in Figure 2A. Note that a good correlation existed between the two tests. In addition, we compared the results of a clinically relevant test based on the Sangtec-Diasorin platform with another commonly employed platform (Roche Diagnostic, Figure 2B). Again, we noted a good correlation between the two systems. These results have shown that there is a significant quantitative difference when comparing results obtained by gel-based analysis versus ELISA-type immunoassay systems. The latter, produced comparable results both quantitatively and qualitatively, suggesting that the use of these clinically relevant platforms leads to meaningful and comparable results.

\section{Molecular Nature of S100B Released by Brain Tissue}

The literature dealing with the detection of $\mathrm{S100B}$ as an indicator of neurological dysfunction or BBB leakage was profoundly affected by the discovery of Marchi, et. al [18] who demonstrated that upon iatrogenic BBB disruption (BBBD) S100B levels were elevated minutes after the procedure itself. This prompted us and others to characterize $\mathrm{S} 100 \mathrm{~B}$ as an indicator of BBB damage rather than a protein related to neuronal cell death or other types of brain injuries [1,2,22-30]. However, recent findings by others $[1,2,13,17,19,22-35]$ have shed doubt on the utility of this approach, primarily because of extracranial sources of S100B. Our data, in fact, show that this is indeed the case and that tissue other than brain expresses this protein. However, it is also known that $\mathrm{S} 100 \mathrm{~B}$ may be detected in its monomeric or dimeric form. In addition, S100B may form a homo- or heterodimer with its companion S100A1 [21,36].
We therefore wished to investigate the molecular nature of the S100B extravasating from the human brain under conditions of iatrogenic BBB disruption (Figure 3). To this end, we utilized ELISA platforms manufactured by Canag/Fujirebo to specifically dissect out the signal components due to homo- or hetero-dimers of S100B and S100A1. In Figure 3, note that BBBD caused an increase of S100B dimer but not of the S100A1-B heterodimer. The increase of the B-B homodimer was the principal event that caused the elevation of the total signal. In other words, these results demonstrated that the main species of S100B released by the brain when the blood-brain barrier is disrupted is the S100 BB. The numbers above the histogram refer to $\mathrm{ng} / \mathrm{mL}$ changes occurred between pre-BBBD and at the time when chemotherapy was injected. Note that virtually all the increase in total S100B measured was due to the B-B dimer $(0.011 \mathrm{ng} / \mathrm{ml})$. The quantitative results for total $\mathrm{S} 100$ are similar to what published previously [2].

\section{Do extracranial sources contribute to the clinical test for serum S100B?}

The results we have presented so far unveiled a complex scenario where several different molecular species act, upon $\mathrm{BBBD}$, to modify serum values of $\mathrm{S} 100 \mathrm{~B}$. We therefore wished to investigate the $\mathrm{S} 100 \mathrm{~B}$ values in serum of patients or controls across, to our knowledge, the broadest published population of subjects. The results are summarized in Figure 4 and Table 1. Given the expression of S100B in adipocytes, we investigated the relationship between fat content and S100B levels. This was achieved by determining body mass index (BMI; see Methods for calculations). Note that when serum samples from 200 subjects were analyzed, no correlation was found between BMI (or body weight in kg, not shown) and S100B levels (Figure 4). This suggests that while unquestionably $\mathrm{S} 100 \mathrm{~B}$ is present in fat, it does not alter the S100B serum concentration in "normal" volunteers, patients affected by a variety of disorders, or pediatric controls or children with various illnesses. These results are also consistent with findings by Biberthaler et al. [27,37-40] who evaluated the relevance of $\mathrm{BMI}$ in serum values of $\mathrm{S100B}$ in a large number of controls and traumatic brain injury patients.

\section{Discussion}

The main contribution of this article to our understanding of S100B use in the clinical setting is that in spite of robust expression by extracranial sources, changes in serum levels are primarily dictated by extravasation across the disrupted BBB. In addition, we have shown that the main molecular species of total S100B related to blood-brain barrier disruption is the $\mathrm{S} 100 \mathrm{~B}$ homodimer. 


\section{Osmotic BBB opening}

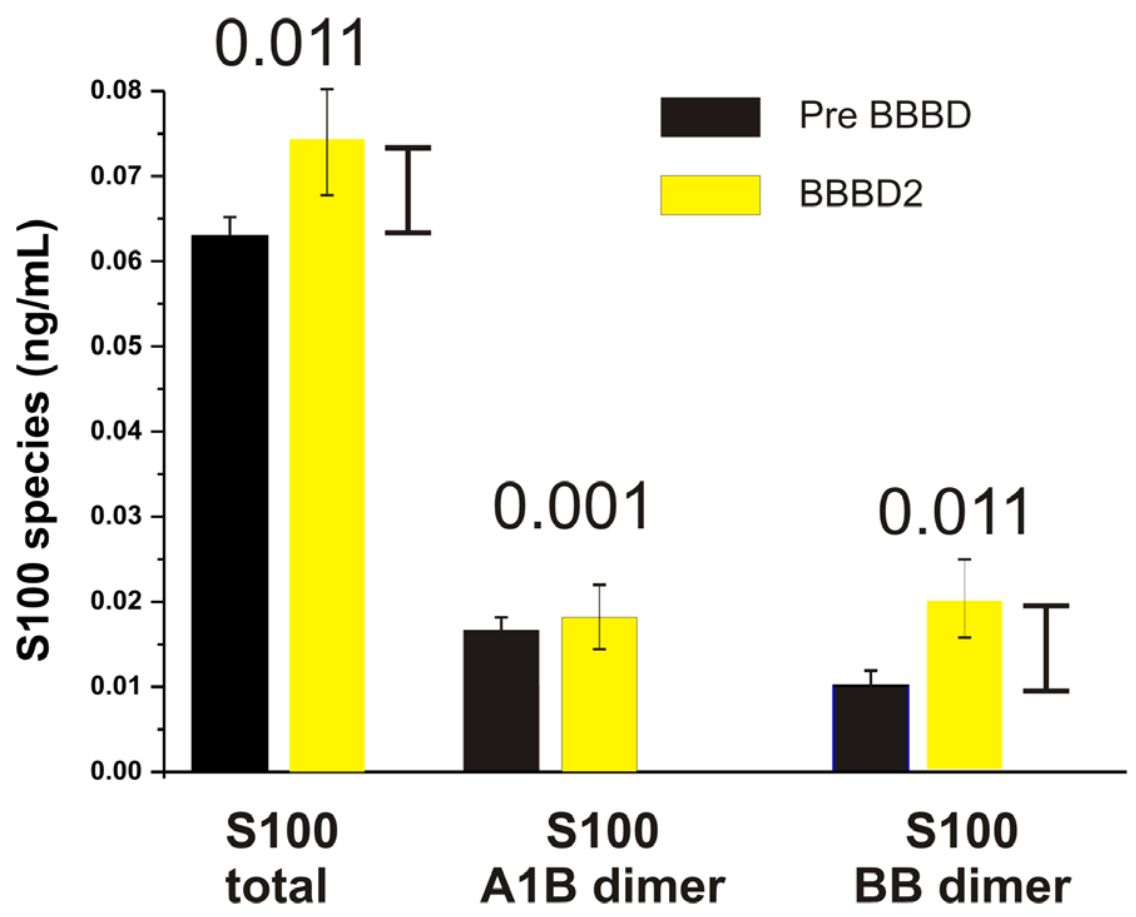

Figure 3. BBB Opening: Comparison of Various Forms of S100B. The main species of $\mathrm{S} 100 \mathrm{~B}$ released from BBB disruption is the B-B dimer as measured using the CanAg/Fujirebio ELISA system. The rise in total S100B after BBB opening was $0.011 \mathrm{ng} / \mathrm{ml}$, which was found to be accounted for by the concomitant rise of the B-B dimer. There was virtually no change in the concentration of the A1-B dimer with BBB opening. We determined the concentration of the A1-B dimer by using the CanAg S100A1B ElA solid-phase, two-step, non-competitive immunoassay based on two mouse monoclonal antibodies specific for two different epitopes specifically expressed in S100A1B. The assay thus determines S100A1B with very low crossreactivity with S100BB or other forms of S100. Similarly, to measure the B-B dimer we used the CanAg S100BB ElA solid-phase, one-step, noncompetitive immunoassay based on two mouse monoclonal antibodies specific for two different epitopes specifically expressed in S100BB. This assay thus determines S100BB with very low cross-reactivity with S100A1B or other forms of S100.

doi:10.1371/journal.pone.0012691.g003

\section{Methodological considerations}

To our knowledge, this is the most exhaustive study ever performed to compare and cross-validate various approaches to the detection of S100B. In addition, we have used a vast array of subjects and tissues. Western blot analysis revealed that, regardless of the antibody used, S100B is found in tissues other than brain. Our results show, surprisingly, a poor correlation between different antibodies. While cross-reactivity of antibodies is well known and widely accepted, we were nevertheless surprised that the rank order of expression depended on the antibodies used. In addition, testing by ELISA showed a different profile, where expression by extracranial sources was less prominent. We were, however, able to show that the gel-based approach was sensitive for S100B which was detected by MS. The co-expression of S100Al was expected, based on results by others [41]. Although discussion of the possibilities of why we observed such varying expressions of S100B protein between the platforms of Western blot and ELISA is a very noteworthy, adequate analysis is beyond the scope of this paper. These findings may have implications beyond recent S100B research efforts, inasmuch as most of our current knowledge on protein function is based on antibody detection of levels by gel electrophoresis. The use of antibody-independent detection therefore appears advisable.

\section{Limitations and strengths for basic scientists}

As stated above, our results are not comforting for the basic scientist. Western blotting is an easy and reproducible technique that enjoys wide popularity. Our concerns are not unique [42]. We found different levels of S100B expression by using two different antibodies and found poor qualitative and quantitative correlation. Similar results were obtained in rodent tissue with other commercially available antibodies (data not shown). Such discrepancies may pose a significant problem, as they substantially impinge on and alter the conclusions drawn from experiments including those aiming at discoveries of disease treatment modalities or with diagnostic purpose.

Another practical limitation of this study, due to the diversity and number of patients included, was the use of the BMI calculation to assess individuals' relative body fat. Recent studies on nutrition and metabolism have validated techniques such as ultrasound, air displacement plethysmography and bioelectrical impedance to be superior to BMI for accurately measuring body fat [43]. These techniques were not readily available nor could we easily implement them and therefore utilized the BMI calculation not only out of practicality, but also out of the widespread use of it in other S100B studies.

Based on these observations, it may be desirable to incorporate any or all of the following to ascertain that an observed signal is 


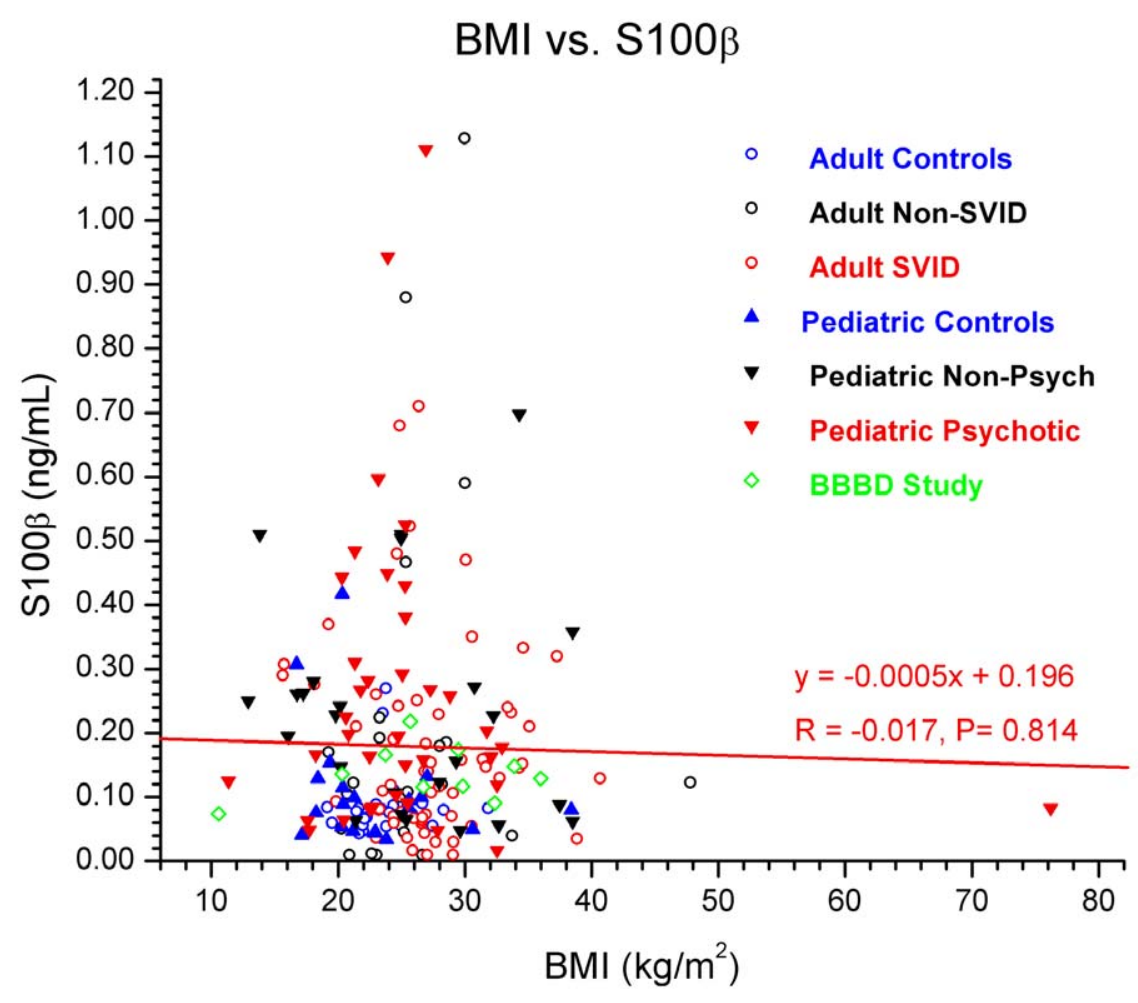

Figure 4. Correlation Between BMI and S100B. Given the expression of S100B in adipocytes, we investigated the relationship between fat content and S100B levels using 200 subjects. No correlation was found between BMI and S100B levels.

doi:10.1371/journal.pone.0012691.g004

indeed reflective of S100B: 1) Protein levels are generally caused by increased mRNA. Therefore, if release of $\mathrm{S} 100 \mathrm{~B}$ is due to a pathology initiating active synthesis rather than by passive release from necrotic astroglial cells (as in stroke) quantitative RT-PCR of S100B messenger RNA would be appropriate to further support any observations; 2) Antibody-independent methods such as MS should be included for validation of target recognition; 3) When possible HPLC (high-performance liquid chromatography) should be used in parallel or serial experiments.

\section{Clinical significance}

While the results we present may be disappointing for the bench researcher, we also demonstrated that the clinical detection of $\mathrm{S} 100 \mathrm{~B}$ is more reproducible and robust. In addition, the type of instrument, or the platform used did not alter the results, nor did it affect the predictive value of the test. The clinical tests all measure total $\mathrm{S} 100 \mathrm{~B}$, regardless of it monomeric or dimeric state, nor do they consider whether S100B is bound to S100B or S100A1. Preliminary results with tests detecting only S100B-S100B dimers have demonstrated, as expected, that the ceiling for "normal values" is significantly lower than the published " $0.1 \mathrm{ng} / \mathrm{ml}$ " dogma $[1,6,10,14,19,24,40,44-46]$.

We confirm that S100B was not exclusively produced by CNS cells. We found that muscle and fat were chief extracranial expressors, which is consistent with the literature [19]. However, our results are in sharp contrast with the findings linking serum S100B to BMI [20]. These results used the same system used by us (LIAMAT), but their sample size was significantly smaller. In addition, no cross-validation with other detection systems was used. Our range of BMI values was larger, the ages broader, and the racial samples were balanced to reflect the general US population. We also included diseased patients' samples, to add to the clinical significance of the findings. We found no correlation between S100B and weight or height, but found, as expected, a correlation with age [47]. When the values were restricted within a given category (e.g., pediatric controls in Table 1), we still found no correlation between BMI and S100B. Why these results are in sharp contrast with Steiner et al. [20] remains at present unknown.

Our results show that extracranial sources of S100B do not significantly affect serum levels. Thus, the reported low sensitivity and positive predictive value (relative to the reported strong specificity and negative predictive value) for S100B [24] is not apparently due to extracranial release of the protein. Further studies are needed to explore the use of S100B dimers as tools in neurodiagnostics.

There are two possible explanations that may account for the discrepancy between previous studies documenting elevated S100B levels from extracranial sources and our present findings. There have been recent reports that serum S100B levels are positively correlated with body mass index without evidence of traumatic brain injuries. Interestingly, obesity has been hypothesized to be a state of heightened systemic oxidative stress and inflammatory response, which is mechanistically linked to other co-morbid conditions such as hypertension and small vessel disease. Therefore, it is not clear whether obesity itself or obesity-associated comorbidities contribute to a rise in serum $\mathrm{S} 100 \mathrm{~B}$ in the previous studies. In our study, we directly measured the tissue specific expression of S100B in addition to serum S100B, which represents a collective source from multiple disease processes. Our study showed that an increase in fat mass might not in isolation be a major contributor to elevated S100B levels. Rather, obesity-related diseases are likely contributors. For example, small vessel ischemic disease associated with obesity is a source of serum S100B $[24,48]$. 
Prior studies have shown that cardiothoracic surgeries resulted in higher serum levels of S100B. However, Fazio et al. demonstrated that S100B antibodies from certain ELISA kits might cross-react with other proteins found in serum[14]. It is difficult to characterize biomarkers in serum because of the wide range of protein concentrations and predominance of 10 to 20 proteins (albumin, immunoglobulins, etc.) that overwhelm the less abundant signals. This may suggest that in other studies yet

\section{References}

1. Kanner AA, Marchi N, Fazio V, Mayberg MR, Koltz MT, et al. (2003) Serum S100beta: a noninvasive marker of blood-brain barrier function and brain lesions. Cancer 97: 2806-2813.

2. Marchi N, Rasmussen PA, Kapural M, Fazio V, Cavaglia M, et al. (2003) Peripheral markers of brain damage and blood-brain barrier dysfunction. Restor Neurol Neurosci 21: 109-121.

3. Blyth BJ, Farhavar A, Gee C, Hawthorn B, He H, et al. (2009) Validation of serum markers for blood-brain barrier disruption in traumatic brain injury. J Neurotrauma 26: 1497-1507.

4. Biberthaler P, Linsenmeier U, Pfeifer KJ, Kroetz M, Mussack T, et al. (2006) Serum S-100B concentration provides additional information for the indication of computed tomography in patients after minor head injury: a prospective multicenter study. Shock 25: 446-453.

5. Ruan S, Noyes K, Bazarian JJ (2009) The economic impact of S-100B as a prehead CT screening test on emergency department management of adult patients with mild traumatic brain injury. J Neurotrauma 26: 1655-1664.

6. Rothermundt M, Ponath G, Arolt V (2004) S100B in schizophrenic psychosis. Int Rev Neurobiol 59: 445-470.

7. Missler U, Wiesmann M, Friedrich C, Kaps M (1997) S-100 protein and neuron-specific enolase concentrations in blood as indicators of infarction volume and prognosis in acute ischemic stroke. Stroke 28: 1956-1960.

8. Griffin WS, Stanley LC, Ling C, White L, MacLeod V, et al. (1989) Brain interleukin 1 and S-100 immunoreactivity are elevated in Down syndrome and Alzheimer disease. Proc Natl Acad Sci U S A 86: 7611-7615.

9. Ingebrigtsen T, Waterloo K, Jacobsen EA, Langbakk B, Romner B (1999) Traumatic brain damage in minor head injury: relation of serum S-100 protein measurements to magnetic resonance imaging and neurobehavioral outcome. Neurosurgery 45: 468-475.

10. Biberthaler P, Mussack T, Wiedemann E, Kanz KG, Koelsch M, et al. (2001) Evaluation of S-100b as a specific marker for neuronal damage due to minor head trauma. World J Surg 25: 93-97.

11. Herrmann M, Curio N, Jost S, Wunderlich MT, Synowitz H, et al. (1999) Protein S-100B and neuron specific enolase as early neurobiochemical markers of the severity of traumatic brain injury. Restor Neurol Neurosci 14: 109-114.

12. Aurell A, Rosengren LE, Karlsson B, Olsson JE, Zbornikova V, et al. (1991) Determination of S-100 and glial fibrillary acidic protein concentrations in cerebrospinal fluid after brain infarction. Stroke 22: 1254-1258.

13. Goncalves CA, Leite MC, Nardin P (2008) Biological and methodological features of the measurement of S100B, a putative marker of brain injury. Clin Biochem 41: 755-763.

14. Fazio V, Bhudia SK, Marchi N, Aumayr B, Janigro D (2004) Peripheral detection of S100beta during cardiothoracic surgery: what are we really measuring? Ann Thorac Surg 78: 46-52.

15. Otto M, Holthusen S, Bahn E, Sohnchen N, Wiltfang J, et al. (2000) Boxing and running lead to a rise in serum levels of S-100B protein. Int J Sports Med 21: $551-555$.

16. Stalnacke BM, Tegner Y, Sojka P (2003) Playing ice hockey and basketball increases serum levels of S-100B in elite players: a pilot study. Clin J Sport Med 13: 292-302.

17. Hasselblatt M, Mooren FC, von Ahsen N, Keyvani K, Fromme A, et al. (2004) Serum S100beta increases in marathon runners reflect extracranial release rather than glial damage. Neurology 62: 1634-1636.

18. Marchi N, Angelov L, Masaryk T, Fazio V, Granata T, et al. (2007) Seizurepromoting effect of blood-brain barrier disruption. Epilepsia 48: 732-742.

19. Anderson RE, Hansson LO, Nilsson O, Liska J, Settergren G, et al. (2001) Increase in serum S100A1-B and S100BB during cardiac surgery arises from extracerebral sources. Ann Thorac Surg 71: 1512-1517.

20. Steiner J, Schiltz K, Walter M, Wunderlich MT, Keilhoff G, et al. (2010) S100B serum levels are closely correlated with body mass index: an important caveat in neuropsychiatric research. Psychoneuroendocrinology 35: 321-324.

21. Donato R (2001) S100: a multigenic family of calcium-modulated proteins of the EF-hand type with intracellular and extracellular functional roles. Int J Biochem Cell Biol 33: 637-668.

22. Marchi N, Cavaglia M, Bhudia S, Hallene K, Janigro D (2004) Peripheral markers of blood-brain barrier damage. Clinica Chimica Acta 342: 1-12.

23. Marchi N, Fazio V, Cucullo L, Kight K, Masaryk TJ, et al. (2003) Serum transthyretin as a possible marker of blood-to-CSF barrier disruption. Journal of Neuroscience 23: 1949-1955. unknown cross-reactants were artificially increasing the apparent S100B levels measured in serum.

\section{Author Contributions}

Conceived and designed the experiments: DJ. Performed the experiments: NP. Analyzed the data: NP VF LC DJ. Contributed reagents/materials/ analysis tools: DJ. Wrote the paper: NP VF LC QT PB JJB DJ.

24. Vogelbaum MA, Masaryk T, Mazzone P, Mekhail T, Fazio V, et al. (2005) S100beta as a predictor of brain metastases: brain versus cerebrovascular damage. Cancer 104: 817-824.

25. Abdul-Khaliq H, Schubert S, Stoltenburg-Didinger G, Troitzsch D, Bottcher W, et al. (2000) Protein S-100beta in brain and serum after deep hypothermic circulatory arrest in rabbits: relationship to perivascular astrocytic swelling. Clin Chem Lab Med 38: 1169-1172.

26. Abdul-Khaliq H, Schubert S, Fischer T, Bottcher W, Harke C, et al. (2000) The effect of continuous treatment with sodium nitroprusside on the serum kinetics of the brain marker protein S-100beta in neonates undergoing corrective cardiac surgery by means of hypothermic cardiopulmonary bypass. Clin Chem Lab Med 38: $1173-1175$.

27. Biberthaler P, Mussack T, Wiedemann E, Kanz KG, Gilg T, et al. (2000) Influence of alcohol exposure on S-100b serum levels. Acta Neurochir Suppl 76: $177-179$.

28. Foerch C, Wunderlich MT, Dvorak F, Humpich M, Kahles T, et al. (2007) Elevated serum S100B levels indicate a higher risk of hemorrhagic transformation after thrombolytic therapy in acute stroke. Stroke 38: 2491-2495.

29. Raabe A, Menon DK, Gupta S, Czosnyka M, Pickard JD (1998) Jugular venous and arterial concentrations of serum S-100B protein in patients with severe head injury: a pilot study. J Neurol Neurosurg Psychiatry 65: 930-932.

30. Watson P, Shirreffs SM, Maughan RJ (2005) Blood-brain barrier integrity may be threatened by exercise in a warm environment. Am J Physiol Regul Integr Comp Physiol 288: R1689-R1694.

31. Pelinka LE, Harada N, Szalay L, Jafarmadar M, Redl H, et al. (2004) Release of $\mathrm{S} 100 \mathrm{~B}$ differs during ischemia and reperfusion of the liver, the gut, and the kidney in rats. Shock 21: 72-76.

32. Savola O, Pyhtinen J, Leino TK, Siitonen S, Niemela O, et al. (2004) Effects of head and extracranial injuries on serum protein S100B levels in trauma patients. J Trauma 56: 1229-1234.

33. Korfias S, Stranjalis G, Papadimitriou A, Psachoulia C, Daskalakis G, et al. (2006) Serum S-100B protein as a biochemical marker of brain injury: a review of current concepts. Curr Med Chem 13: 3719-3731.

34. Dassan P, Keir G, Brown MM (2009) Criteria for a clinically informative serum biomarker in acute ischaemic stroke: a review of S100B. Cerebrovasc Dis 27 : 295-302.

35. Geyer C, Ulrich A, Grafe G, Stach B, Till H (2009) Diagnostic value of S100B and neuron-specific enolase in mild pediatric traumatic brain injury. J Neurosurg Pediatr 4: 339-344.

36. Nylen K, Ost M, Csajbok LZ, Nilsson I, Hall C, et al. (2008) Serum levels of $\mathrm{S} 100 \mathrm{~B}, \mathrm{~S} 100 \mathrm{~A} 1 \mathrm{~B}$ and S100BB are all related to outcome after severe traumatic brain injury. Acta Neurochir (Wien) 150: 221-227.

37. Biberthaler P, Mussack T, Wiedemann E, Kanz KG, Mutschler W, et al. (2002) Rapid identification of high-risk patients after minor head trauma (MHT) by assessment of S-100B: ascertainment of a cut-off level. Eur J Med Res 7: 164-170.

38. Biberthaler P, Mussack T, Wiedemann E, Gilg T, Soyka M, et al. (2001) Elevated serum levels of S-100B reflect the extent of brain injury in alcohol intoxicated patients after mild head trauma. Shock 16: 97-101.

39. Mussack T, Biberthaler P, Kanz KG, Wiedemann E, Gippner-Steppert C, et al. (2002) Serum S-100B and interleukin-8 as predictive markers for comparative neurologic outcome analysis of patients after cardiac arrest and severe traumatic brain injury. Crit Care Med 30: 2669-2674.

40. Mussack T, Biberthaler P, Wiedemann E, Kanz KG, Englert A, et al. (2000) S$100 \mathrm{~b}$ as a screening marker of the severity of minor head trauma (MHT)-a pilot study. Acta Neurochir Suppl 76: 393-396.

41. Baudier J, Gerard D (1986) Ions binding to S100 proteins. II. Conformational studies and calcium-induced conformational changes in S100 alpha alpha protein: the effect of acidic $\mathrm{pH}$ and calcium incubation on subunit exchange in S100a (alpha beta) protein. J Biol Chem 261: 8204-8212.

42. Mann M (2008) Can proteomics retire the western blot? J Proteome Res 7: 3065.

43. Pineau JC, Guihard-Costa AM, Bocquet M (2007) Validation of ultrasound techniques applied to body fat measurement. A comparison between ultrasound techniques, air displacement plethysmography and bioelectrical impedance vs. dual-energy X-ray absorptiometry. Ann Nutr Metab 51: 421-427.

44. Anderson RE, Hansson LO, Nilsson O, Dijlai-Merzoug R, Settergren G (2001) High serum S100B levels for trauma patients without head injuries. Neurosurgery 48: 1255-1258. 
45. Jonsson H, Johnsson P, Hoglund P, Alling C, Blomquist S (2000) Elimination of S100B and renal function after cardiac surgery. J Cardiothorac Vasc Anesth 14: 698-701.

46. Raabe A, Kopetsch O, Woszczyk A, Lang J, Gerlach R, et al. (2003) Serum S$100 \mathrm{~B}$ protein as a molecular marker in severe traumatic brain injury. Restor Neurol Neurosci 21: 159-169.
47. Portela LV, Tort AB, Schaf DV, Ribeiro L, Nora DB, et al. (2002) The serum S100B concentration is age dependent. Clin Chem 48: 950-952.

48. Mazzone PJ, Marchi N, Fazio V, Taylor JM, Masaryk T, et al. (2009) Small vessel ischemic disease of the brain and brain metastases in lung cancer patients. PLoS One 4: e7242. 